\title{
Green roofs and green façades for improving sustainability of towns
}

\author{
C. Bibbiani1a, A. Campiotti², G. Giagnacovo², L. Incrocci ${ }^{3}$, A. Pardossi ${ }^{3}$, A. Latini², E. Schettini ${ }^{4}$ \\ and G. Vox ${ }^{4}$
}

${ }^{1}$ Dept. of Veterinary Science, University of Pisa, Italy; ${ }^{2}$ ENEA - Italian National Agency for New Technologies, Energy and Sustainable Economic Development, Rome, Italy; ${ }^{3}$ Dept. of Agriculture, Food and Environment, University of Pisa, Italy; ${ }^{4}$ Dept. of Agricultural and Environmental Science, University of Bari, Italy

\begin{abstract}
Nowadays, buildings in Europe account for a consume of $40 \%$ of total energy use and about $65 \%$ of total electricity consumption. According to the European Directive on the energy performance of buildings (EPBD Directive), solutions such as green roofs and green walls can help to reduce energy consumptions and the Greenhouse gases emissions by buildings. The installation of plant systems covering some surfaces of the building allows to reach an improvement of the building's energy efficiency mainly by reducing the energy demand for cooling in warm periods. The green layers used for buildings contribute to improve thermal insulation, since they reduce the direct solar radiation while the evaporative cooling contributes to create a better local microclimate. This paper provides the first data collected by a green wall prototype in progress at ENEA Casaccia Centre to investigate the effects of this natural green solution on the energy efficiency of buildings. The project was funded by the Programme Research of Electrical System, and is being carrying on in cooperation with the Universities of Pisa, Bari and Viterbo.
\end{abstract}

Keywords: energy efficiency, green roof, green walls, GRW, green infrastructures, urban ecology

\section{INTRODUCTION}

Within the 20-20-20 by 2020 strategy the EU agreed on a threefold set of targets addressing greenhouse gas (GHG) emissions, renewable energies (RES) and energy efficiency (EE). Since buildings are responsible for $40 \%$ of energy consumption and $36 \%$ of CO2 emissions in the EU Directive Energy Performance of Buildings (European Union, 2011). One of the ways to improve energy efficiency in the buildings sector is to promote plant systems like green roof (GRF) and green wall (GRW), mainly in commercial and civil buildings. The use of vegetation contribute to ameliorate the negative thermal effects of conventional building since plants of GRW absorb most solar radiation (evapotranspiration, photosynthesis, etc.) releasing water vapour which increase the air humidity and decreasing the air temperature. GRWs are also in tune with the Directive on the energy performance of buildings which outlines that GI (Green Infrastructures) solutions such as green roofs and walls can help reduce GHG emissions on urban areas, and improve the appearance of the cities (European Commission, 2013). In addition, the Covenant of Mayors of European Commission outlined to develop innovative technologies to combating the Urban Heat Island Effect (UHI, an elevation of temperature due to the high concentration of heat absorbed and re-irradiated by rooftops and pavements) through green roofs and walls or networks of green spaces as ventilation areas.

\footnotetext{
a E-mail: carlo.bibbiani@unipi.it
} 


\section{GREEN ROOF AND GREEN WALLS}

Today, establishing vegetation on rooftops and walls of buildings attract more and more attention in many cities of the world. Green Roofs and Walls systems offers a number of benefits e.g.: minimize contaminants from rainwater, reduce potential damages from storm-water, and contribute to improve environmental quality of urban areas. If widely adopted in the cities, GRW can also reduce the UHI Effect and hence greenhouse gas (GHG) emissions, and thus contributing significantly to both the sustainability and aesthetical environment of cities (Santamouris, 2012; Schettini et al., 2016).

The selection of native plant species with suitable characteristics as low water demand, speed of growing, disease and pest resistance, transmissivity and reflectivity power, represents another important area of research (Trepanier et al., 2009). Therefore, a number of regulations were established to define standards and guidelines for designing and constructing buildings incorporating of GRF systems (Perini, 2013). Furthermore, this plant technology today is also regarded as an important solution for improving energy efficiency of buildings by reducing energy demand of HVAC systems especially in summer periods (Kumar and Kaushik, 2005; Campiotti et., 2017). In order to evaluate the capacity of plant species on the variation of cooling load demand in buildings, some authors (Ariaudo et al., 2009; Campiotti et al., 2013; Vox et al., 2017) took into account the density of the plant leaves, defined as "green factor" by the equation (1):

$\mathrm{K}_{\mathrm{g}}=\left(\mathrm{T}_{\mathrm{s}}-\mathrm{T}_{\mathrm{gw}}\right) /\left(\mathrm{T}_{\mathrm{s}}-\mathrm{T}_{\text {air }}\right)=1-\tau_{\mathrm{g}} \cdot \mathrm{h}_{\mathrm{e}} / \mathrm{h}_{\mathrm{e}}{ }^{*}$

where:

$\tau_{\mathrm{g}}=$ solar transmission coefficient of the green layer,

$\mathrm{h}_{\mathrm{e}}, \mathrm{h}_{\mathrm{e}}{ }^{*}=$ surface heat transfer coefficient without and with the green layer,

$\mathrm{T}_{\mathrm{gw}}=$ external surface temperature of the green wall,

$\mathrm{T}_{\mathrm{s}}=$ external surface temperature of the bare wall,

$\mathrm{T}_{\mathrm{air}}=$ external air temperature.

The $\mathrm{K}_{\mathrm{g}}$ factor varies between 0 and 1 , the former when no temperature decrease is obtained by the green wall, the latter when $T_{g w}$ is equal to $T_{\text {air. }}$ The coefficients $\tau_{g}$ and $h_{e}{ }^{*}$ come from test values and therefore the $\mathrm{K}_{\mathrm{g}}$ factor can be easily calculated by the reported equation. Many possibilities exist for constructing GRWs, depending on the characteristics of both buildings and local climate. Whenever possible it is advisable to leave a small gap between the wall of the building and the supporting structure in order to maximize the effects of summer cooling and winter insulation (chimney effect). However, for reasons of eco-sustainability, the plant systems should use only raining and/or recycled water distributed by hydroponics closed-loop systems, provided with a biofiltration systems to allow to capture, reuse and treat nutrient solutions and water.

Although data on GRWs are available from a number of areas (mainly Germany, France and Italy in Europe, North America and many countries in Asia), most of them are not transferable to specific climatic conditions of other countries. Thus, ENEA has started a project action at the Centre ENEA, located north of Rome (latitude: $42^{\circ} 02^{\prime} 36 "$, longitude: $12^{\circ} 18^{\prime} 28^{\prime \prime}$ ) (Figure 1). The objective of this project was to start collecting data to define materials, energetic parameters, plant species, and information on construction, maintenance and costs of GRW. The plant grow system is fed by a nutrient solution which is re-circulated from a manifold, and then collected in a gutter were is filtered and recirculated to the plants.

A set of different plant species were grown on the wall, i.e.: Hedera elix, Lonicera holprolifici, Partenocissus quinquefolia, Trachelosperum jasminoides. The experimental data were collected by means of a data logger (CR10X, Campbell, Logan, UT, USA). 

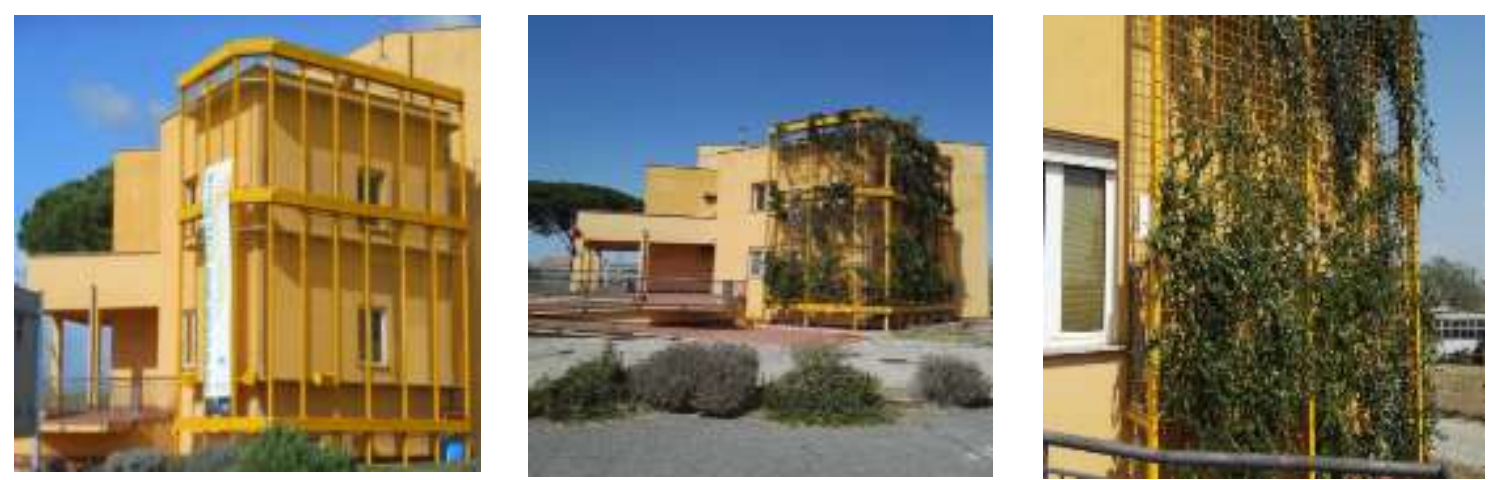

Figure 1. Green wall prototype installed at the ENEA Casaccia Centre.

The data were measured at a frequency of $60 \mathrm{~s}$, averaged every 15 min and stored in the data logger, by a pyranometer (CMP6-L, Campell, Logan, UT, USA) for the solar radiation, and by Rotronic-Hygroclip-S3 sensors for the external air temperature. The temperature of the external plaster surfaces exposed to the solar radiation was measured using thermistors (Tecno.El S.r.l., Rome, Italy).
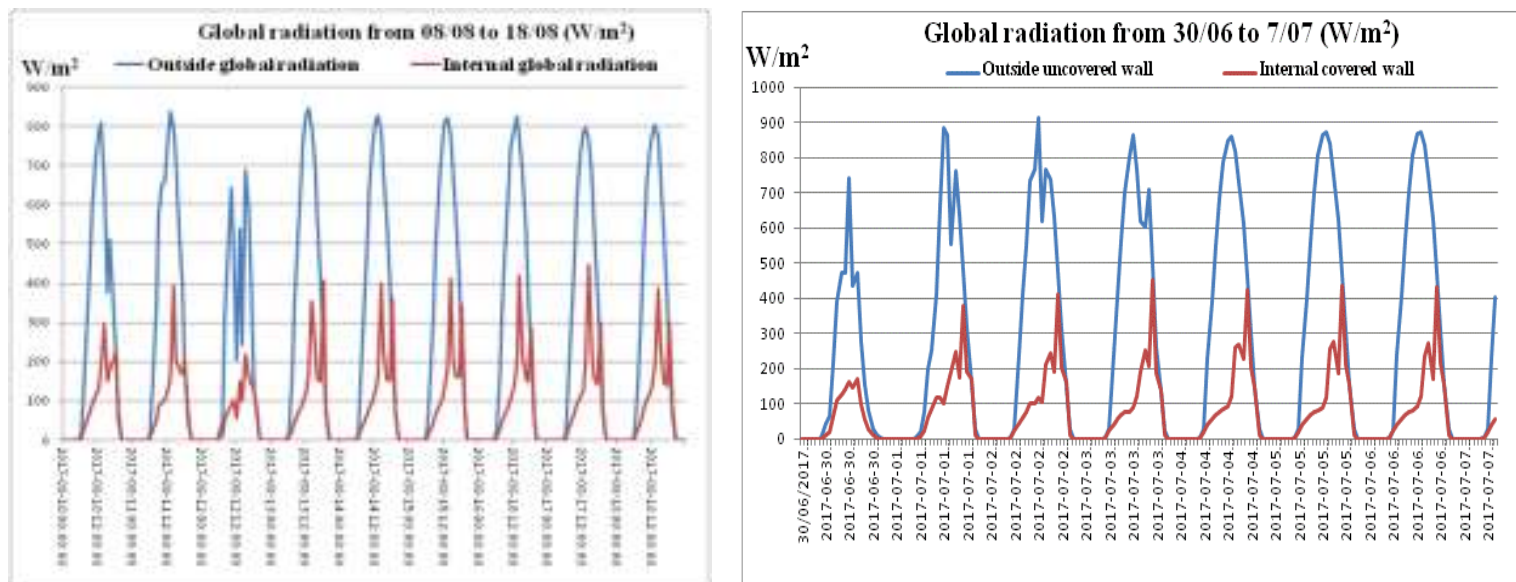

Figure 2. Variation of solar radiation on the wall
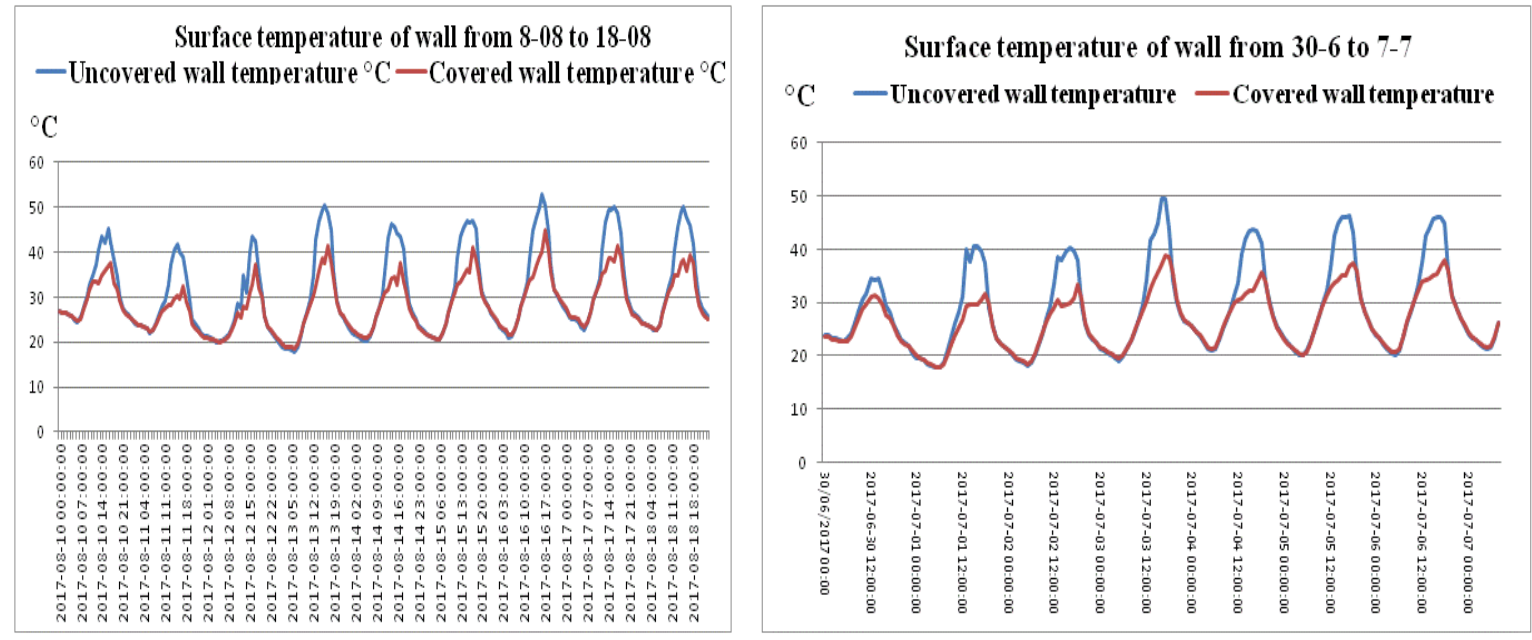

Figure 3. Variation of wall temperature

From the first data, it is strongly evident how the green covering reduces the incidence of solar radiation and the temperature of the building's walls. This is more evident during the warmer periods as shown in Figure 2 and Figure 3. 


\section{RESULTS AND DISCUSSIONS}

The first data collected on the ENEA prototype of a green wall showed a strong reduction of the solar radiation values on the wall shaded with the plants which led to a lower external temperature of the wall in comparison with the wall not covered with the plant system. However, there is still a lack of quantifiable data to definitely accounts the benefits that the plant system can really provide to the energy efficiency of the test-building.

However, the GRW application represents an entirely new market opportunity for a number of companies, with benefits for the entire economic of cities. On the other hand, this natural solution can identify and encourage synergies between adapting buildings to climate change and mitigating their GHG emissions, recognizing potential for multiple benefits. Governments should encourage GRW systems, especially in densely populated urban areas in order to cut solar heat gain thus reducing the building energy-use in summer, also with benefit for the heat island effect in metropolitan cities. A widespread use of the different typologies of GRWs can become a part of the actions response to the objectives of both the Kyoto Protocol and the European Energy Efficiency Directive. Furthermore, new building constructions should include systems which use the grey-water coming from the building itself, in order to save the building's potable water use. Features should also include photovoltaic systems to produce the energy needed autonomously.

\section{CONCLUSIONS}

Further work at ENEA will focus on the study of energy efficiency performances of both the roof and the walls of buildings provided with vegetated surfaces, in order to allow collection of data to fully explore the mechanisms underlying the energy efficiency potential of plant systems, and to develop a technical guide with the blue lines for the sustainable application of GRWs in cities.

\section{REFERENCES}

Ariaudo F., Fracastoro G.V., Corgnati S. (2009). Cooling Load reduction by green walls. Atti del convegno IBPC, Istanbul, 2009.

Campiotti C.A., Schettini E., Bibbiani C., Alonzo G., Viola C. (2013). Scarascia Mugnozza G., Blanco I., Vox G. Building green coverings for a sustainable use of energy. Journal of Agricultural Engineering 2013; volume XLIV(s2):e50.

Campiotti C., Giagnacovo G., Latini A., Scoccianti M., Viola C., Consorti L. (2017). Caratterizzazione di tipologie di sistemi vegetali per migliorare l'efficienza energetica degli edifici nella città metropolitana. ENEA, Ricerca di Sistema Elettrico, PAR 2015 (in Italian).

European Union (2010). Making our cities attractive and sustainable. How the EU contributes to improving the urban environment. ISBN 978-92-79-16298-5 doi: 10.2779/42720.

European Commission (2013). European Commission (2013). Building a Green Infrastructure for Europe. ISBN 978-92-79-33428-3. doi: 10.2779/54125. (C) European Union, 2013.

Kumar R., Kaushik S.C. (2005). Performance evaluation of green roof and shading for thermal protection of buildings, Building and Environment, vol.40, pp.1505-1511, 2005.

Perini K. (2013). Retrofitting with vegetation recent building heritage applying a design tool—the case study of a school building. Frontiers of Architectural Research (2013) 2, 267-277.

Santamouris M. (2012) Cooling the cities - a review of reflective and green roof mitigation technologies to fight heat island and improve comfort in urban environments. Solar Energy 103: 682-703, http://dx.doi.org/10.1016/j.solener.2012.07.003.

Schettini E., Blanco I., Campiotti C.A., Bibbiani C., Fantozzi F., Vox G. (2016). Green control of microclimate in buildings. Agriculture and Agricultural Science Procedia 8 ( 2016 ) 576 - 582.

Trepanier M., Boivin M.A., Lamy M.B., Dansereau B. (2009). Green Roof and living walls, Chronica Horticulture, 149 (2), 2009.

Vox G., Blanco I, Fuina S., Campiotti C.A., Scarascia Mugnozza G., Schettini E. (2017). Evaluation of wall surface temperatures in green facades. Proceedings of the Institution of Civil Engineers. Engineering Sustainability http://dx.doi.org/10.1680/jensu.16.00019. 